\title{
Enhanced Surface Precipitates on Ultrafine-Grained Titanium in Physiological Solution
}

\author{
Qing Zhou *, Lei Wang and Cheng-Hong Zou \\ College of Mechanical and Electrical Engineering, Nanjing University of Aeronautics and Astronautics, \\ Nanjing 210007, China; wlhomura@gmail.com (L.W.); zchnzs@163.com (C.-H.Z.) \\ * Correspondence: anzhouqing@nuaa.edu.cn; Tel.: +86-138-1409-0311
}

Received: 17 May 2017; Accepted: 27 June 2017; Published: 1 July 2017

\begin{abstract}
Enhanced cell adherence to the surface of nanocrystallized commercially pure titanium (CP-Ti) was observed by several authors. However, the understanding of the surface modification of $\mathrm{Ti}$ in a physiological solution due to nanocrystallized grain size has not been reached. In this work, equal channel angular pressing (ECAP) was applied to manufacturing ultrafine grained CP-Ti. Martensite and Widmanstatten microstructures were also obtained for comparison. The CP-Ti pieces with different microstructures were subjected to soaking tests in a simulated body fluid. Electrochemical impedance spectroscopy (EIS) measurements, X-ray photoelectron spectroscopy (XPS) and scanning electron microscope (SEM), energy dispersive spectrometer (EDS) were used to characterize the surfaces. The results show the surface precipitates mainly contain $\mathrm{Ti}, \mathrm{O}, \mathrm{Ca}$ and $\mathrm{P}$. The quantity of precipitates on ECAPed $\mathrm{CP}-\mathrm{Ti}$ is the largest among different specimens corresponded to the observation of the thickest layer formation on ECAPed CP-Ti found by EIS. EDS results show more $\mathrm{CaPO}$ and less Ti are included on ECAPed Ti comparing to the deposits on other two types of specimens. Smaller numbers of precipitates and denser film are produced on the surface of the water-quenched $\mathrm{CP}-\mathrm{Ti}$. The regeneration kinetics of the $\mathrm{CaP}$ precipitates evaluated by Gibbs free energy is introduced to interpret the precipitating behaviors on different $\mathrm{CP}-\mathrm{Ti}$ specimens.
\end{abstract}

Keywords: surface performance; CaP precipitates; ultrafine grain size; ECAP; EIS; XPS; CP-Ti

\section{Introduction}

Titanium and titanium alloys are potential materials for biomedical application due to their high mechanical properties and high corrosion resistance. Pure titanium occupies the strength lower than Ti-6Al-4V, for example, for no alloys addition to pure titanium. However its strength can be elevated through microstructural modification by severe plastic deformation (SPD). Not only strength, but also corrosion resistance and surface cells attachment can be improved by the method of SPD [1-8]. The strength increment is correlated to ultrafine grain size given by Hall-Petch relationship. However, until now the mechanism of improved cell attachment and corrosion resistance of titanium metal affected by grain size has not been understood.

Kim [1] and Park [2] established a model explaining enhanced surface cell attachment on nanocrystallized $\mathrm{CP}-\mathrm{Ti}$ is due to that the nodule at triple-point junction of grain microstructure is increased in number as the grain size is refined through equal channel angular pressing (ECAP). Accelerated stem cell attachment on ECAPed CP-Ti specimens was observed by Estrin [3]. Enhanced bacterials adhesion on nanocrystalline $\mathrm{CP}-\mathrm{Ti}$ was reported by the paper performed by Truong [4]. Nano size surface roughness produced on the nanocrystalline grained titanium is considered as the mechanisms by them. Faghihi [5] investigated the effect of grain orientation on MC3T3 pre-osteoblast cell attachment on titanium alloy (Ti-6Al-4V). His finding emphasizes that the orientation of grain microstructure has great influence on the number of pre-osteoblast cells attached to the surface of titanium. 
Native formed surface film on titanium experiences regeneration process occurring in a corrosive solution. The surface compositions are eventually modified to the compositions included in the solution. The studies of the reaction of native surface on titanium with the physiological solution were performed by authors [9-18]. Lu [9] studied the reaction of a polycrystalline titanium surface with oxygen and water molecules at $150-850 \mathrm{~K}$. The oxidations types are varied according to the temperatures of reaction. The study by Alkhateeb [10] confirmed a spontaneous modification of the Ti surface to the surface containing $\mathrm{Ca}$ and $\mathrm{P}$ species as the surface contacted with a Ringer's solution. His study also revealed the composition of the $\mathrm{CaP}$ precipitates changed as a function of time. The interaction between Ti and Dulbecco's modified Eagle's medium with bovine serum albumin (BSA) component was studied by Burgos-Asperilla [11] who reported that the passive film has acidic hydroxyl group and the adsorption kinetics for phosphate and calcium ions is slow.

Although these studies, the investigation of the mechanism behind the effect of nanostructure on the cell attachment of $\mathrm{CP}-\mathrm{Ti}$ are still open. Furthermore, in the scope of authors' knowledge, no study concerns the reaction of titanium surface with physiological solution affected by ultrafine grained microstructure until now. In this paper, an investigation of spontaneous modification of the surface of titanium with different substrate microstructures after soaking in a physiological solution is carried out. Electrochemical impedance spectroscopy (EIS), X-ray photoelectron spectroscopy (XPS) and scanning electron microscope (SEM) are used for surface characterization and the composition quantity measurements.

\section{Materials and Methods}

A commercially pure titanium (CP-Ti, Grade 2$)$ bar is used. The ECAP die used in this work has channel angle $\Phi$ of $105^{\circ}$ and outer corner angle $\Psi$ of $75^{\circ}$. The die and a furnace were fixed on a hydraulic press (Tianjing Forging Machine, Tianjing, China). Isothermal ECAP at the temperature of $400{ }^{\circ} \mathrm{C}$ was applied. The ECAP process was carried out through 2 passes with route Bc which means the rod is rotated $90^{\circ}$ clockwise continuously along its longitudinal axis in the next ECAP pass.

After roughly grinding, the CP-Ti pieces were heated in an argon atmosphere up to $900{ }^{\circ} \mathrm{C}$ and held at the temperature for $1 \mathrm{~h}$. Then they were separately quenched into water or cooled within the furnace to the room temperature. These specimens were named as WQ (water quenching) and FC (furnace cooling) specimen, respectively. Three same pieces were prepared for each condition for the reliability of the experiment. After ground with 400, 800 and 1200 abrasive paper, the surface of titanium was polished with two kinds of $\mathrm{Al}_{2} \mathrm{O}_{3}$ powder W2 (average diameter $2 \mu \mathrm{m}$ ) and W0.5 (average diameter $0.5 \mu \mathrm{m}$ ). The samples further electrochemically polished were observed by electronic backscatter diffraction (EBSD) attached to a scanning electron microscope (SEM) (JSM-7001F, Japan Electron Optics Laboratory Co. Ltd., Tokyo, Japan).

Simulated body fluid (SBF) solution which composition is $7.885 \mathrm{NaCl}, 0.219 \mathrm{KCl}, 0.268 \mathrm{CaCl}_{2}$, $0.081 \mathrm{Na}_{2} \mathrm{SO}_{4}, 0.311 \mathrm{MgCl}_{2} \cdot 6 \mathrm{H} 2 \mathrm{O}, 0.340 \mathrm{NaHCO}_{3}, 0.219 \mathrm{~K}_{2} \mathrm{HPO}_{4}, 6.048 \mathrm{NH}_{2} \mathrm{C}\left(\mathrm{CH}_{2} \mathrm{OH}\right)$ and $0.8 \mathrm{~g} / \mathrm{L}$ bovine serum albumin (BSA, Aladdin, Shanghai, China) was used for the media. The partial pressure of oxygen was reduced by the nitrogen gas injection (ASTM F2129-06). Adjust the $\mathrm{pH}$ value of the test solution with $\mathrm{HCl}(1 \mathrm{M})$ to 7.4. The whole preparation process of SBF was carried out in a constant temperature water bath $\left(37.0 \pm 1.0^{\circ} \mathrm{C}\right)$. Finally bovine serum albumin was added to the SBF solution.

The CP-Ti pieces after ECAP and heat treatments were first ground and polished equally and then ultrasonically cleaned, firstly by suds for $15 \mathrm{~min}$, then by acetone for $15 \mathrm{~min}$. The samples were finally cleaned by deionized water and dried in the air. On the surface of Ti pieces, an area of $1 \mathrm{~cm} \times 1 \mathrm{~cm}$ was left and other places were coated by epoxy resin. The electrochemical cell is maintained, by means of a thermostated bath at constant temperature and defined $\left(37^{\circ} \mathrm{C}\right)$. Typical three electrodes system (Chi660D, Shanghai, China) called working electrode, saturated calomel electrode (SCE) (reference electrode) and platinum foil (auxiliary electrode) was used. The open-circuit potential was first measured for $1 \mathrm{~h}$ until the open-circuit potential was stable. Afterwards, electrochemical 
impedance spectroscopy (EIS) was measured at open-circuit potential in the frequency range from $100 \mathrm{kHz}$ to $10 \mathrm{mHz}$ with a perturbation signal of $5 \mathrm{mV}$ (vs. SCE).

The preparation of the samples for static immersion tests was basically the same as that for the EIS measurement. The pieces mounted in cold-setting resin with $1 \mathrm{~cm} \times 1 \mathrm{~cm}$ window left as working area were subjected to static immersion tests. Each specimen was leaned against wall of a $25 \mathrm{~mL}$ beaker and fully immersed in the solution. The beaker was covered with a laboratory Parafilm sheet and filled with pure nitrogen above the solution. All beakers were placed in a water-bath circumstance and held at $37^{\circ} \mathrm{C}$ for 60 days. Three sets of experiments under one identical condition were carried out in order to ensure high reliability.

After immersion, the pieces were cleaned with deionized water three times and dried in the air. The chemical composition of the surface was examined by a PHI Quantera II X-ray Photoelectronic Spectroscopy (XPS, PHI, Chanhassen, MN, USA) with a monochromatic AlK X-ray source, and pass energies of 280 and $112 \mathrm{eV}$ for survey and high-resolution scan, respectively. A take-off angle of $45^{\circ}$ to the surface normal was used in the XPS tests for all samples. The surface morphology of the specimen after immersion was observed by a SEM (JSM-7001F).

\section{Results}

\subsection{Microstructure}

Figure 1 shows EBSD mappings of the CP-Ti specimens. In Figure 1a, a shear band microstructure composed of fine grains with low angle and high angle boundaries is shown. An average grain size of $3.3 \pm 1.2 \mu \mathrm{m}$ is obtained. The microstructure of WQ specimens is composed of coarse grains (Figure $1 \mathrm{~b}$ ) and a few martensitic bundles in the grain. The martensite contains lamellas structure with the lamellas space ranged in the order of $10 \mu \mathrm{m}$. Most of lamellas boundaries are low angle type. Coarse Widmanstatten phase is presented in FC specimen (Figure 1c). The boundaries of the Widmanstatten phase are mainly large angle type.

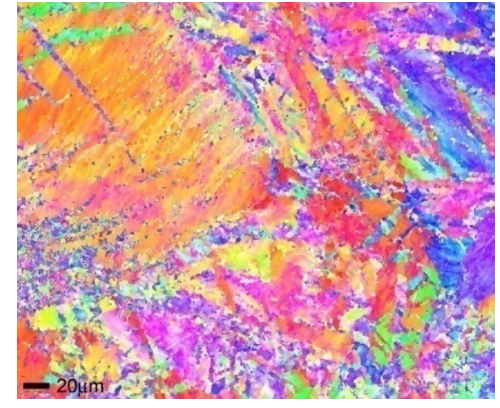

(a)

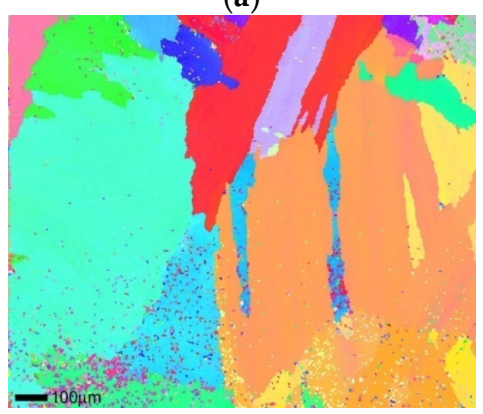

(c)

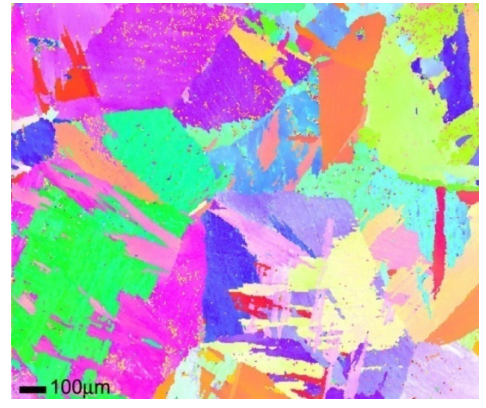

(b)

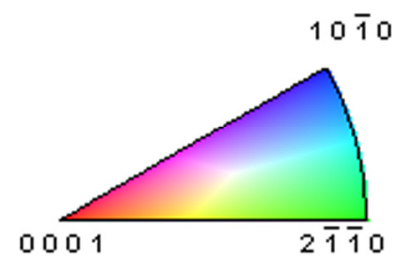

Figure 1. Electronic backscatter diffraction (EBSD) mapping of the microstructures of (a) equal channel angular pressing (ECAP); (b) water quenching (WQ); and (c) Furnace cooling (FC) CP-Ti. 


\subsection{Electrochemical Impedance Spectroscopy (EIS) Results}

Figure 2a,b shows respectively Nyquist and Bode plots of CP-Ti specimens at the open circuit potential. Nyquist plots (Figure 2a) exhibit a deformed semicircle, resulting from a dispersion effect. The diameter of the semicircle, representing the real impedance indicates the magnitude of the corrosion resistance. The Nyquist plots of the WQ and FC specimens in the low frequency range exhibit a straight line with a $45^{\circ}$ angle to the $Z^{\prime}$ axis, indicating the existence of Warburg impedance [19] and a diffusion of the corrosion product: ions across the surface film of the electrode. The Bode plots (Figure 2b) show that the impedance modulus of ECAPed CP-Ti is higher than those of WQ and FC CP-Ti. The Bode plots of WQ and FC specimens at low frequencies also show the features of Warburg impedance. For all specimens, the EIS spectra are characterized with one time constant.

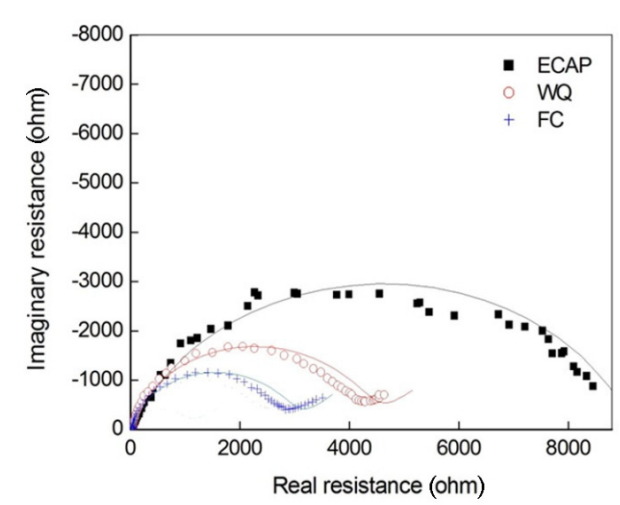

(a)

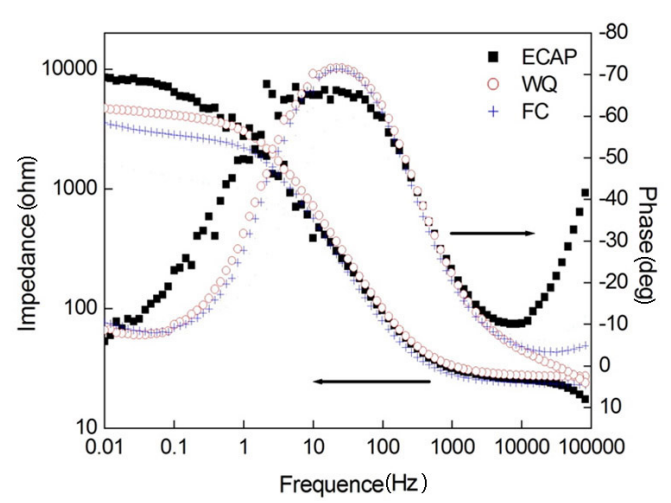

(b)

Figure 2. (a) Nyquist plots; and (b) Bode plots of CP-Ti after ECAP and heat treatments.

Using ZSimpWin software (Echem Software, Ann Arbor, MI, USA), equivalent electrical circuit is used to simulate EIS curves under best fitting. Figure 3 shows the simulated results of the equivalent electrical circuits and $R(Q R)$ and $R(Q(R W))$ is corresponding to the circuits of ECAPed and heat-treated $\mathrm{CP}-\mathrm{Ti}$, respectively. The fitting parameters of the equivalent electrical circuits for various specimens are listed in Table 1 . It can be seen from Table 1 that the solution resistance $R_{\mathrm{S}}$ of three types of specimens is almost the same due to the same solution used. The charge transfer resistance of ECAPed specimen is the highest among these specimens indicating the highest corrosion resistance and the thickest layer produced on the surface [20]. The Warburg capacitance is inversely proportional to the Warburg impedance. It is found that the Warburg capacitance for WQ CP-Ti is lower than that for FC CP-Ti. This observation indicates a denser film produced on WQ CP-Ti [21] causing more difficulty of the ions diffusion across the surface on WQ CP-Ti. A schematic diagram of the layers produced on two kinds of specimens is shown in Figure 3.

Several authors [22-24] concerned porous layer formation during corrosion tests on titanium and titanium alloys. The feature of porous in this work can be demonstrated by the EIS result of insignificance of Warburg impedance for ECAPed specimens and easy diffusion behavior of corrosion product through the layer. The evidence of larger phase angles of ECAPed CP-Ti (Figure 2b) at low frequencies than those of FC and WQ CP-Ti also supports the feature of porous. Therefore, a thick porous layer formation on ECAPed $\mathrm{Ti}$ is concluded. $\mathrm{TiO}_{x}$ denotes titanium is bonded to oxygen by $\mathrm{X}=$ $2,1,3 / 2$ and $3 / 4$. 


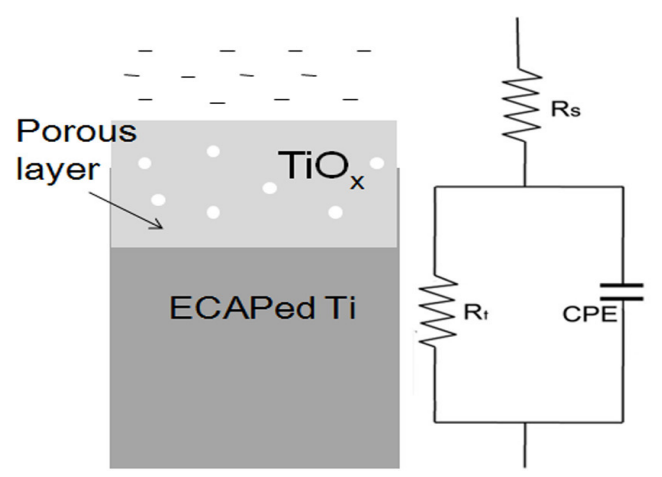

(a)

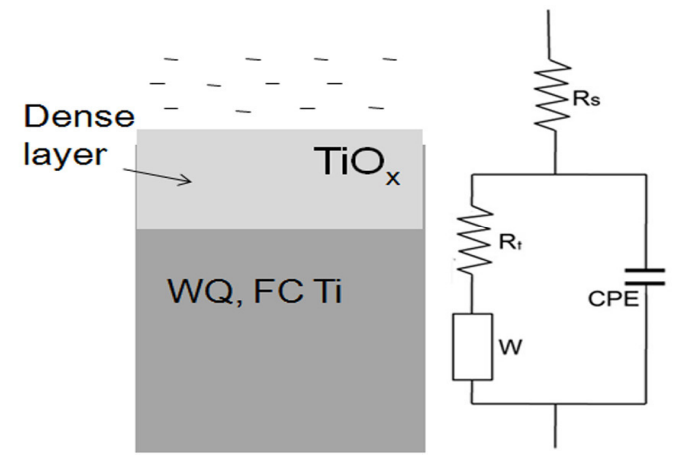

(b)

Figure 3. Equivalent electric circuits by best fitting simulation of the data obtained from electrochemical impedance spectroscopy (EIS) measurement of (a) ECAP CP-Ti; and (b) FC and WQ CP-Ti specimens.CPE: constant phase element, $R_{\mathrm{s}}$ : solution resistance, $R_{\mathrm{t}}$ : charge transfer resistance, $W$ : Warburg element.

Table 1. Equivalent electric circuit parameters for CP-Ti.

\begin{tabular}{|c|c|c|c|c|c|}
\hline $\begin{array}{l}\text { Specimen } \\
\text { Types }\end{array}$ & $R_{\mathrm{S}}\left(\Omega \cdot \mathrm{cm}^{2}\right)$ & $Q\left(\Omega^{-1} \cdot \mathrm{cm}^{-2} \cdot \mathrm{s}^{n}\right)$ & $n$ & $R_{\mathrm{t}}\left(\Omega \cdot \mathrm{cm}^{2}\right)$ & $\begin{array}{c}\sigma \\
\left(\Omega^{-1} \cdot \mathrm{cm}^{-2} \cdot \mathrm{s}^{0.5}\right)\end{array}$ \\
\hline FC & $\begin{array}{c}21.82+ \\
2.27 /-4.17\end{array}$ & $(5.54+2.34 /-1.28) \times 10^{-5}$ & $\begin{array}{c}0.863+ \\
0.034 /-0.035\end{array}$ & $\begin{array}{c}1201.13+ \\
467.9 /-45.5\end{array}$ & $\begin{array}{c}0.0063+ \\
0.0019 /-0.0021\end{array}$ \\
\hline WQ & $\begin{array}{c}25.19+ \\
2.66 /-3.39\end{array}$ & $(4.42+3.04 /-2.12) \times 10^{-5}$ & $\begin{array}{c}0.882+ \\
0.048 /-0.054\end{array}$ & $\begin{array}{c}4452.0+ \\
664 /-157\end{array}$ & $\begin{array}{c}0.0049+ \\
0.0012 /-0.0020\end{array}$ \\
\hline ECAP & $21.5 \pm 5.93$ & $(7.85 \pm 1.07) \times 10^{-5}$ & $0.773 \pm 0.019$ & $6043.5 \pm 733.5$ & - \\
\hline
\end{tabular}

\subsection{Response to Soaking}

The surface composition and morphology of various titanium specimens after soaking is characterized by XPS, SEM and EDS. O 1s, N 1s, Ti 2p, Ca $2 p$ and P $2 p$ spectra are presented in XPS survey scan of various titanium specimens. There is no difference on the element type, however, the atomic percentage of the elements (Table 2) detected by XPS varies according to the specimen type. The maximum $\mathrm{O}$ and Ti contents were observed on ECAPed CP-Ti and the $\mathrm{O}$ and Ti contents on FC $\mathrm{CP}-\mathrm{Ti}$ are higher than those on WQ one. P on ECAPed specimen has higher content than other two type specimens. Ca content on ECAPed Ti is the same $(=0.5$ at $\%)$ as those on FC Ti, and Ca deposited on WQ Ti is very small $(<0.1$ at $\%)$.

Table 2. Surface film composition and atomic percentage measured semi-quantitatively by X-ray photoelectron spectroscopy (XPS) on CP-Ti after soaking in simulated body fluid (SBF) (at \%).

\begin{tabular}{cccccc}
\hline Sample & O 1s & Ti 2p & Ca 2p & P 2p & N 1s \\
\hline ECAP & 36.2 & 20.3 & 0.5 & 1.0 & 1.6 \\
FC & 31.2 & 17.5 & 0.5 & 0.4 & 1.7 \\
WQ & 22.2 & 17.2 & $<0.1$ & $<0.1$ & 4.3 \\
\hline
\end{tabular}

High resolution spectra of various elements are shown in Figures 4-7. The $\mathrm{O} 1 \mathrm{~s}$ peak is deconvoluted into two sub-peaks: the peak attributed to oxygen bonds in organic at binding energy of around $531.9 \mathrm{eV}$ and to metal-oxygen bonds at binding energy of around $529.9 \mathrm{eV}$ (Figure 4a). For comparing the photoelectron intensity activated from different types of specimens, the background intensity was cut (Figure $4 \mathrm{~b}$ ). It is found from the intensity contributed by ECAPed CP-Ti is the highest and the intensity contributed by FC Ti is higher than that by WQ Ti, which denotes the O content in the surface of different Ti specimens can be ranged in the order, ECAP $>$ FC $>$ WQ. 


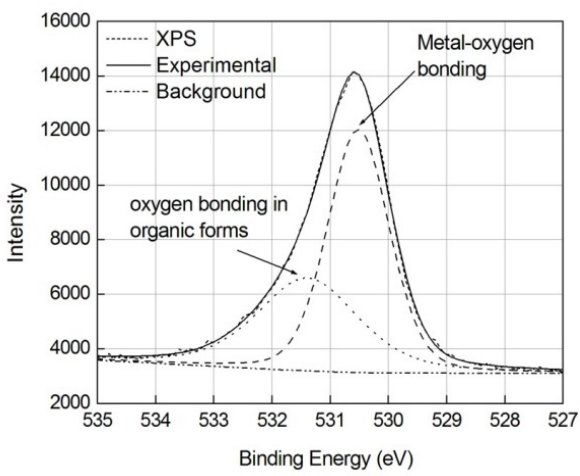

(a)

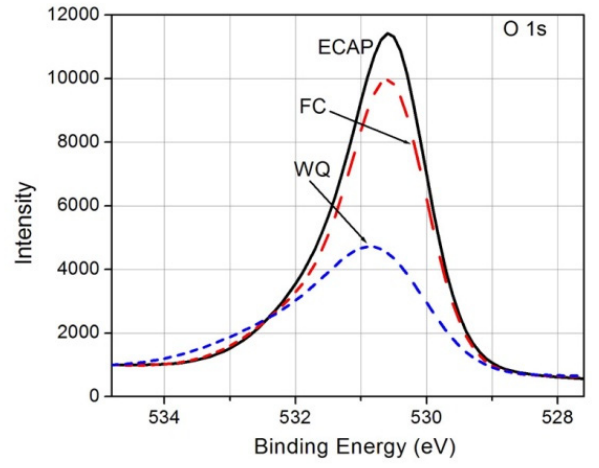

(b)

Figure 4. High resolution spectra of $\mathrm{O}$ 1s on CP-Ti after soaking in simulated body fluid (SBF). (a) ECAPed CP-Ti; and (b) Comparison of three types of specimens: ECAPed, FC and WQ.

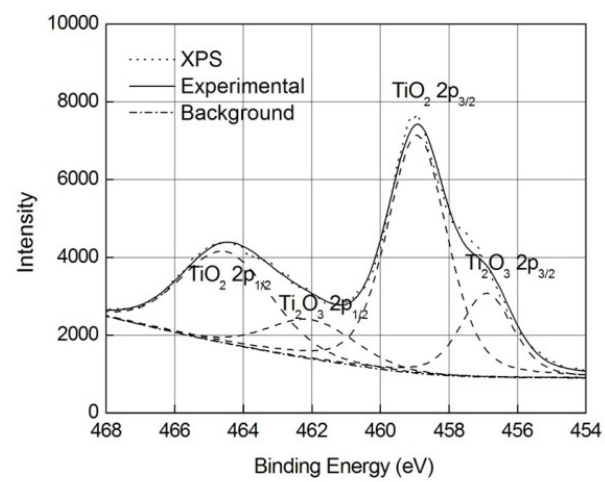

(a)

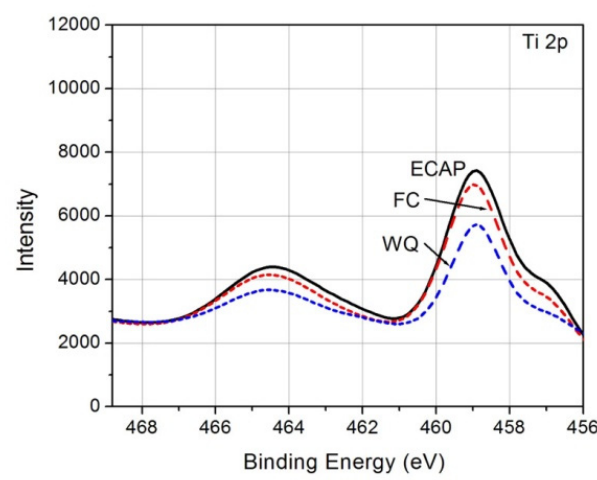

(b)

Figure 5. High resolution spectra of Ti $2 \mathrm{p}$ on $\mathrm{CP}-\mathrm{Ti}$ after soaking in SBF. (a) ECAPed CP-Ti; and (b) Comparison of three types of specimens: ECAPed, FC and WQ.

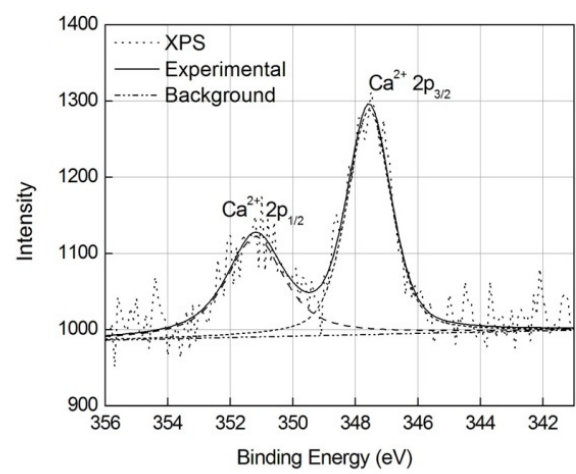

(a)

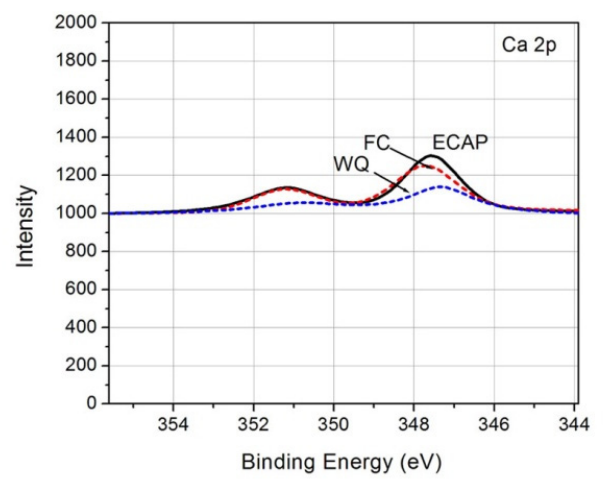

(b)

Figure 6. High resolution spectra of $\mathrm{Ca} 2 \mathrm{p}$ on $\mathrm{CP}-\mathrm{Ti}$ after soaking in SBF. (a) ECAPed CP-Ti; and (b) Comparison of three types of specimens: ECAPed, FC and WQ. 


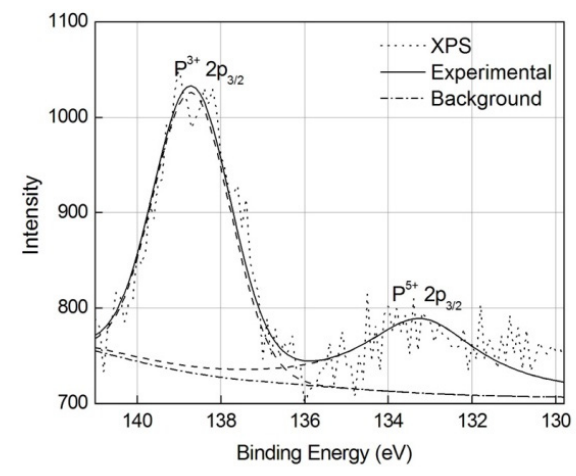

(a)

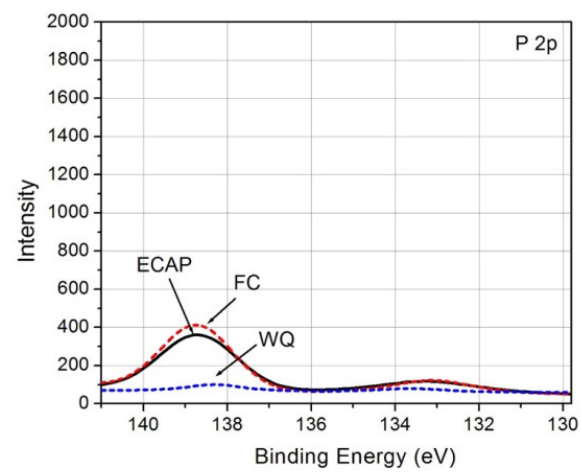

(b)

Figure 7. High resolution spectra of P $2 \mathrm{p}$ on CP-Ti after soaking in SBF. (a) ECAPed CP-Ti; and (b) Comparison of three types of specimens: ECAPed, FC and WQ.

The Ti $2 p$ spectra show two types, Ti $2 \mathrm{p} \mathrm{Ti}^{4+}$ and Ti $2 \mathrm{pTi}^{3+}$ (Figure 5a). They both are spin-orbit splitting at $2 \mathrm{p} 1 / 2$ and $2 \mathrm{p} 3 / 2$. It can be seen that the amount of $\mathrm{Ti}^{4+}$ is much larger than $\mathrm{Ti}^{3+}$. The Ti $2 \mathrm{p}$ intensity of different specimens is compared in Figure $5 b$. Higher intensity of Ti $2 p$ on ECAPed and FC $\mathrm{CP}-\mathrm{Ti}$ than on WQ CP-Ti is observed.

The Ca $2 p$ spectra (Figure 6a) show spin-orbit splitting at 2p1/2 and 2p3/2 and binding energy at 351.1 and $347.6 \mathrm{eV}$, respectively. The intensity of Ca $2 p$ contributed by ECAPed and FC CP-Ti is higher than that by WQ Ti. The P $2 p$ spectra (Figure $7 a$ ) show $\mathrm{P}^{3+} 2 \mathrm{p} 3 / 2$ at $138.6 \mathrm{eV}$ and $\mathrm{P}^{5+} 2 \mathrm{p} 3 / 2$ at $133.5 \mathrm{eV}$. $\mathrm{CaHPO}_{4}$ and $\mathrm{Ca}_{3}\left(\mathrm{PO}_{4}\right)_{2}$ are possible according to the bonding energy of $\mathrm{Ca} 2 \mathrm{p}$ and $\mathrm{P} 2 \mathrm{p}$ [25]. The semi-quantitative comparison of different types of specimens shown in Figures $6 \mathrm{~b}$ and $7 \mathrm{~b}$ indicates larger numbers of depositions containing $\mathrm{Ca}$ and $\mathrm{P}$ produced on ECAPed and FC specimens than those produced on WQ specimens.

An observation of the surface morphology by a SEM is shown in Figure 8. Two kinds of depositions, light and dark particles are exhibited on the titanium matrix. Dark particles are significantly larger in number than light particles. It can be found that the number of dark particles is the largest on ECAPed Ti and the least on WQ one (Figure 8a,c). The EDS results examining the composition of light, dark particles and that of matrix are listed in Table 3. EDS results indicate that the dark and light particles are both composed of $\mathrm{Ti}, \mathrm{O}, \mathrm{Ca}$ and $\mathrm{P}$. The dark particles on ECAPed CP-Ti consist of more $\mathrm{O}$ and less Ti compared with those on FC and WQ CP-Ti. The atomic ratio between $\mathrm{Ca}$ and $\mathrm{P}(\mathrm{Ca}: \mathrm{P})$ is ranged in 1:0.6 1:7.4. A higher ratio (1:4.7-7.4) and also more $\mathrm{P}$ content are produced on ECAPed CP-Ti surface. The Ca:P ratio measured on FC CP-Ti is 1:0.65 1:0.77.

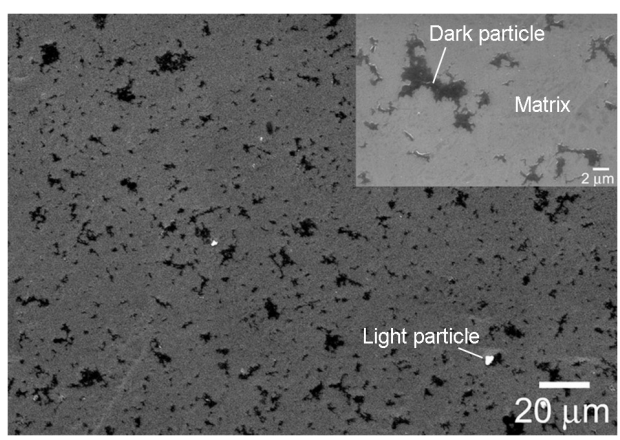

(a)

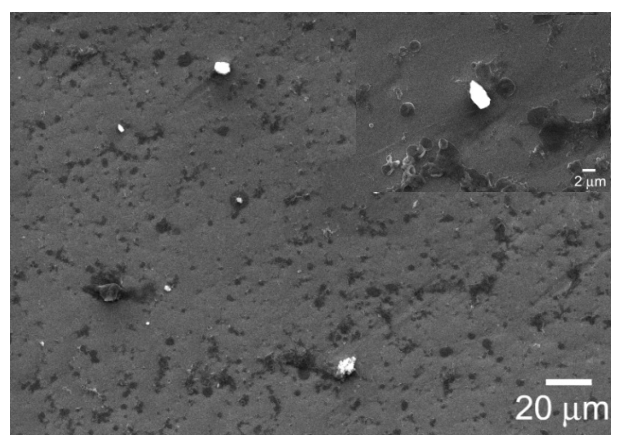

(b)

Figure 8. Cont. 


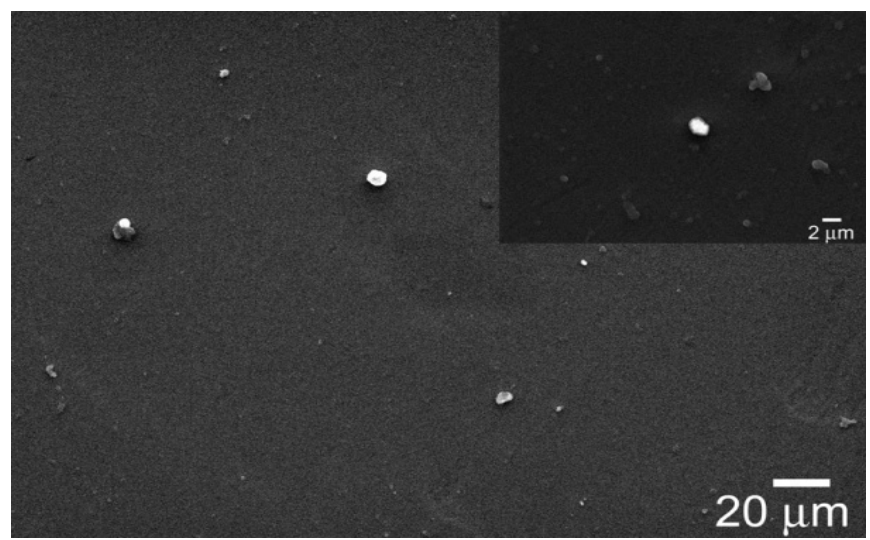

(c)

Figure 8. Scanning electron microscope (SEM) photographs of (a) ECAP; (b) FC; (c) WQ CP-Ti after soaking in SBF.

Table 3. Energy dispersive spectrometer (EDS) atomic percentages of the elements deposited on ECAP, FC and WQ CP-Ti (at \%) and Ca:P ratio.

\begin{tabular}{ccccccc}
\hline \multirow{2}{*}{ Specimens } & $\begin{array}{c}\text { Measured } \\
\text { Places }\end{array}$ & $\mathbf{O}$ & $\mathbf{T i}$ & $\mathbf{P}$ & $\mathbf{C a}$ & Ca:P \\
& Matrix & 13.72 & 74.18 & 0.152 & 0 & - \\
\multirow{2}{*}{ ECAP-1 * } & Dark particle & 16.08 & 55.66 & 0.127 & 0.016 & $1: 7.7$ \\
& Matrix & 12.34 & 72.18 & 0 & 0.019 & - \\
\multirow{2}{*}{ ECAP-2 } & Dark particle 1 & 17.55 & 46.86 & 0.076 & 0.015 & $1: 5.2$ \\
& Dark particle 2 & 13.73 & 54.24 & 0.114 & 0.024 & $1: 4.7$ \\
\hline \multirow{3}{*}{ FC-1 } & Matrix & 3.49 & 92.54 & 0.015 & 0.023 & $1: 0.6$ \\
& Light particle & 12.84 & 58.83 & 0.295 & 0.441 & $1: 0.7$ \\
& Dark particle & 8.01 & 61.89 & 0.033 & 0.043 & $1: 0.8$ \\
\hline \multirow{2}{*}{ FC-2 } & Matrix & 4.27 & 91.00 & 0.116 & 0 & - \\
& Light particle & 53.40 & 9.29 & 0 & 0 & - \\
& Dark particle & 6.28 & 78.04 & 0.026 & 0 & - \\
\hline \multirow{2}{*}{ WQ-1 } & Matrix & 4.36 & 82.86 & 0.068 & 0 & - \\
& Light particle & 37.88 & 16.36 & 0.081 & 0.070 & $1: 1.2$ \\
\hline \multirow{2}{*}{ WQ-2 } & Matrix & 4.00 & 91.44 & 0.145 & 0 & - \\
& Dark particle 1 & 6.18 & 81.33 & 0.147 & 0 & - \\
& Dark particle 2 & 3.61 & 90.37 & 0.187 & 0 & - \\
\hline
\end{tabular}

* ECAP-1 and ECAP-2 mean two ECAPed specimens are examined by EDS.

\section{Discussion}

The composition of CaP compound spontaneously formed on titanium surface will be changed with the increase of deposition time [15]. The chemical reaction taken place firstly is the formation of $\mathrm{PO}_{4}$ ion then the deposition of Ca. The chemical reaction proposed by Hanawa [15] associated with surface dissolution of titanium oxide is firstly

$$
\mathrm{TiO}(\mathrm{OH})_{2}+\mathrm{HPO}_{4}{ }^{2-} \rightarrow \mathrm{TiO}(\mathrm{HPO} 4)+2 \mathrm{OH}^{-},
$$

and then

$$
\mathrm{TiO}\left(\mathrm{HPO}_{4}\right)+\mathrm{Ca}^{2+}+2 \mathrm{OH}^{-} \rightarrow \mathrm{CaTiO}\left(\mathrm{HPO}_{4}\right)(\mathrm{OH})_{2} .
$$

Previous studies [22,26] on partial dissolution behaviour happening on titanium surface revealed hydrated porous structure formation and surface chemical composition modification. From this work 
it can be found that the ultrafine grained microstructure does promote the surface precipitates of $\mathrm{CaP}$ compound formation on titanium. The effect of microstructure is attributed to the formation kinetics of $\mathrm{CaP}$ compound. The $\mathrm{CaP}$ formation kinetics can be evaluated by Gibbs free energy occurring in the reactions of Equations (1) and (2). Gibbs free energy is a thermodynamic potential that can be used to calculate the maximum work performed by a chemical reaction at a constant temperature and pressure. An increase of the Gibbs free energy leads to an intensive chemical reaction expressed by in the Equations of (1) and (2) and more product quantity of CaP. The stored energy $E_{\mathrm{D}}$ associated with severe plastic deformation and grain size is given by [27].

$$
E_{\mathrm{D}}=\mathrm{k} \theta / D,
$$

where $\mathrm{k}$ is the constant, $\theta$ is the tilt angle of the boundary and $D$ is the grain size. The grain boundaries is separated into high angle boundary and low angle boundary by the title angle where $\theta \leq 15^{\circ}$ defined as low angle boundary and $>15^{\circ}$ defined as high angle boundary. From Equation (3) the smaller the grain size is, the larger the stored energy. If we correlate the stored energy with Gibbs free energy, it is to some degree understandable that the surface precipitates on ultrafine grained titanium are larger.

Surface roughness of titanium is another important issue affecting the surface attaching properties $[3,4]$. In this work, the specimen surface is treated with the same grinding and polishing process as described in the experimental. The surface roughness is attempted to ensure the same for different kinds of specimens.

More CaP deposition is believed to promote osteoblast cell growth and attachment on titanium [28-30] because CaP is necessary component composing osteoblast cells. Therefore the increased osteoblast cell attachment on ECAPed CP-Ti can be understood by this mechanism.

\section{Conclusions}

The surface modification on CP-Ti specimens soaked in a pure $\mathrm{N}_{2}$ bubbled simulated body fluid with BSA addition due to different microstructure of substrate was investigated. ECAPed CP-Ti has a microstructure of ultrafine grain size averagely $3.3 \mu \mathrm{m}$, whereas FC and WQ CP-Ti has developed coarse grained Widmanstatten and martensite microstructure, respectively. The EIS measurement shows a larger charge transfer resistance for ECAPed CP-Ti than FC and WQ CP-Ti indicating a thicker film formation on ECAPed CP-Ti. A larger Warburg resistance is obtained on WQ CP-Ti specimens indicates a denser film formation on WQ CP-Ti.

The surface composition and morphology of different titanium specimens after 60 days soaking in the SBF solution are examined by XPS, EDS and SEM. It is found that the precipitates amount on ECAPed CP-Ti is the largest among three kinds of specimens. The precipitates contain $\mathrm{O}, \mathrm{Ti}, \mathrm{Ca}$ and P. More contents of O, Ti, Ca and P are deposited on the ECAPed CP-Ti. An increase of Ca:P ratio can be examined on ECAPed surface explaining that the $\mathrm{P}$ amount deposited on the surface of ECAPed Ti is increased comparing to other two type of specimens. These phenomena are attempted to be interpreted by the concept of Gibbs free energy of the surface reaction. Because of increased dislocation density and decreased grain size induced by ECAP process the store energy is increased and consequently the Gibbs free energy is higher, which leads to the increased amount of precipitates on ECAPed Ti. Enhanced osteoblast cell attachment on ultrafine grained Ti observed previously can be understood by this mechanism. A smaller amount of compound deposited on WQ CP-Ti may be related to the denser film formation on WQ CP-Ti.

This investigation is an attempt to understand how the microstructure of Ti substrate affects the chemical composition change of the Ti surface immersed in a SBF with BSA addition. More Ca, P and $\mathrm{O}$ contents are found in the surface composition on ultrafine grained Ti which do benefit to the bioactivity improvement of Ti implant practically. This finding provides a method for improving bio-bonding between implant and surround tissue. 
Acknowledgments: Thanks for the grant from Jiangsu Natural Science Foundation (BK2011736).

Author Contributions: Q.Z. conceived and designed the experiments; C.H.Z. performed the experiments; Q.Z. and L.W. analyzed the data; Q.Z. wrote the paper.

Conflicts of Interest: The founding sponsors had no role in the design of the study; in the collection, analyses, or interpretation of data; in the writing of the manuscript, and in the decision to publish the results.

\section{References}

1. Kim, T.N.; Balakrishnan, A.; Lee, B.C.; Kim, W.S.; Dvorankova, B.; Smetana, K.; Park, J.K.; Panigrahi, B.B. In vitro fibroblast response to ultra fine grained titanium produced by a severe plastic deformation process. J. Mater. Sci. Mater. Med. 2008, 19, 553-557. [CrossRef] [PubMed]

2. Park, J.-W.; Kim, Y.-J.; Park, C.H.; Lee, D.-H.; Kod, Y.G.; Jang, J.-H.; Lee, C.S. Enhanced osteoblast response to an equal channel angular pressing-processed pure titanium substrate with microrough surface topography. Acta Biomater. 2009, 5, 3272-3280. [CrossRef] [PubMed]

3. Estrin, Y.S.; Ivanova, E.P.; Michalska, A.; Truong, V.K.; Lapovok, R.; Boyd, R. Accelerated stem cell attachment to ultrafine grained titanium. Acta Biomater. 2011, 7, 900-906. [CrossRef] [PubMed]

4. Truong, V.K.; Lapovok, R.; Estrin, Y.S.; Rundell, S.; Wang, J.Y.; Fluke, C.J.; Crawford, R.J.; Ivanova, E.P. The influence of nano-scale surface roughness on bacterial adhesion to ultrafine-grained titanium. Biomaterials 2010, 31, 3674-3683. [CrossRef] [PubMed]

5. Faghihi, S.; Azari, F.; Li, H.; Bateni, M.R.; Szpunar, J.A.; Vali, H.; Tabrizian, M. The significance of crystallographic texture of titanium alloy substrates on pre-osteoblast responses. Biomaterials 2006, 27, 3532-3539. [CrossRef] [PubMed]

6. Maleki-Ghaleh, H.; Hajizadeh, K.; Hadjizadeh, A.; Shakeri, M.S.; Alamdari, S.; Ghobadi Masoudfar, S.; Aghaie, E.; Javidi, M.; Zdunek, J.; Kurzydlowski, K.J. Electrochemical and cellular behavior of ultrafine-grained titanium in vitro. Mater. Sci. Eng. C 2014, 39, 299-304. [CrossRef] [PubMed]

7. An, B.; Li, Z.; Diao, X.; Xin, H.; Zhang, Q.; Jia, X.; Wu, Y.; Li, K.; Guo, Y. In vitro and in vivo studies of ultrafine-grain Ti as dental implant material processed by ECAP. Mater. Sci. Eng. C 2016, 67, 34-41. [CrossRef] [PubMed]

8. Zheng, C.Y.; Nie, F.L.; Zheng, Y.F.; Cheng, Y.; Wei, S.C.; Valiev, R.Z. Enhanced in vitro biocompatibility of ultrafine-grained titanium with hierarchical porous surface. Appl. Surf. Sci. 2011, 257, 5634-5640. [CrossRef]

9. Lu, G.; Bernasek, S.L.; Schwartz, J. Oxidation of a polycrystalline titanium surface by oxygen and water. Surf. Sci. 2000, 458, 80-90. [CrossRef]

10. Alkhateeb, E.; Virtanen, S. Influence of surface self-modification in Ringer's solution on the passive behavior of titanium. J. Biomed. Mater. Res. Part A 2005, 75, 934-940. [CrossRef] [PubMed]

11. Burgos-Asperilla, L.; Garcia-Alonso, M.C.; Escudero, M.L. Study of the interaction of inorganic and organic compounds of cell culture medium with a Ti surface. Acta Biomater. 2010, 2, 652-661. [CrossRef] [PubMed]

12. Matykina, E.; Arrabal, R; Valiev, R.Z.; Molina-Aldareguia, J.M.; Belov, P.; Sabirov, I. Electrochemical anisotropy of nanostructured titanium for biomedical implants. Electrochim. Acta 2015, 176, 1221-1232. [CrossRef]

13. Hodgson, A.W.E.; Mueller, Y.; Forster, D.; Virtanen, S. Electrochemical characterization of passive film on Ti alloys under simulated biological conditions. Electrochim. Acta 2002, 47, 1913-1923. [CrossRef]

14. Hanawa, T.; Ota, M. Calcium phosphate naturally formed on titanium in electrolyte solution. Biomaterials 1991, 12, 767-774. [CrossRef]

15. Hanawa, T.; Asami, K.; Asaoka, K. Repassivation of titanium and surface oxide film regenerated in simulated bioliquid. J. Biomed. Mater. Res. 1998, 40, 530-538. [CrossRef]

16. Wu, W.; Nancollas, G.H. Kinetics of heterogeneous nucleation of calcium phosphates on anatase and rutile. J. Colloid Interface Sci. 1998, 199, 206-211. [CrossRef]

17. Lima, J.; Sousa, S.R.; Ferreira, A.; Barbosa, M.A. Interactions between calcium, phosphate, and albumin on the surface of titanium. J. Biomed. Mater. Res. 2001, 55, 45-53. [CrossRef]

18. Healy, K.E.; Ducheyne, P. Hydration and preferential molecular adsorption on titanium in vitro. Biomaterials 1992, 13, 553-561. [CrossRef]

19. Skale, S.; Dolecek, V.; Slemnik, M. Substitution of the constant phase element by Warburg impedance for protective coating. Corros. Sci. 2007, 49, 1045-1055. [CrossRef] 
20. Tamilselvi, S.; Raman, V.; Rajendran, N. Corrosion behaviour of Ti-6Al-7Nb and Ti-6Al-4V ELI alloys in the simulated body fluid solution by electrochemical impedance spectroscopy. Electrochim. Acta 2006, 52, 839-846. [CrossRef]

21. Yuan, X.X.; Xu, N.X. Determination of hydrogen diffusion coefficient in metal hydride electrode by modified Warburg impedance. J. Alloys Comp. 2001, 329, 115-120. [CrossRef]

22. Cvijović-Alagić, I.; Cvijović, Z.; Bajat, J.; Rakin, M. Composition and processing effects on the electrochemical characteristics of biomedical titanium alloys. Corros. Sci. 2014, 83, 245-254. [CrossRef]

23. Assis, S.L.; Wolynec, S.; Costa, I. The electrochemical behaviour of Ti-13Nb-13Zr alloy in various solutions. Mater. Corros. 2008, 59, 739-743. [CrossRef]

24. Alves, V.A.; Reis, R.Q.; Santos, I.C.B.; Souza, D.G.; Goncalves, T.F.; Pereirada-Silva, M.A.; Rossi, A.; Silva, L.A. In situ impedance spectroscopy study of the electrochemical corrosion of $\mathrm{Ti}$ and $\mathrm{Ti}-6 \mathrm{Al}-4 \mathrm{~V}$ in simulated body fluid at $25^{\circ} \mathrm{C}$ and $37^{\circ} \mathrm{C}$. Corros. Sci. 2009, 51, 2473-2482. [CrossRef]

25. National Institute of Standards and Technology (NIST) XPS Database Selected Element Search Menu. Available online: http://srdata.nist.gov/xps/selEnergyType.aspx (accessed on 5 October 2015).

26. Pan, J.; Thierry, D.; Leygraf, C. Electrochemical impedance spectroscopy study of the passive oxide film on titanium for implant application. Electrochim. Acta 1996, 41, 1143-1153. [CrossRef]

27. Humphreys, F.J.; Hatherly, M. Recrystallization and Related Annealing Phenomenon, 2nd ed.; Elsevier: Oxford, UK, 2004; pp. 12-24.

28. Oliveira, N.C.M.; Moura, C.C.G.; Zanetta-Barbosa, D.; Mendonça, D.B.S.; Cooper, L.; Mendonça, G.; Dechichi, P. Effects of titanium surface nodization with CaP incorporation on human osteoblastic response. Mater. Sci. Eng. C 2013, 33, 1958-1962. [CrossRef] [PubMed]

29. Carlier, A.; Chai, Y.C.; Moesen, M.; Theys, T.; Schrooten, J.; Van Oosterwyck, H.; Geris, L. Designing optimal calcium phosphate scaffold-cell combinations using an integrative model-based approach. Acta Biomater. 2011, 7, 3573-3585. [CrossRef] [PubMed]

30. Hong, Y.J.; Chun, J.-S.; Lee, W.-K. Association of collagen with calcium phosphate promoted osteogenic responses of osteoblast-like MG63 cells. Colloids Surf. B Biointerfaces 2011, 83, 245-253. [CrossRef] [PubMed]

(C) 2017 by the authors. Licensee MDPI, Basel, Switzerland. This article is an open access article distributed under the terms and conditions of the Creative Commons Attribution (CC BY) license (http:/ / creativecommons.org/licenses/by/4.0/). 